\title{
Different doses of galcanezumab versus placebo in patients with migraine and cluster headache: a meta-analysis of randomized controlled trials
}

\author{
Yanbo Yang ${ }^{1 \dagger}$, Zilan Wang ${ }^{1 \dagger}$, Bixi Gao ${ }^{1}$, He Xuan ${ }^{2}$, Yun Zhu' ${ }^{1}$ Zhouqing Chen ${ }^{1 *}$ and Zhong Wang ${ }^{1 *}$ (D)
}

\begin{abstract}
Background: Galcanezumab is a novel monoclonal antibody that target to calcitonin gene-related peptide (CGRP). It has been tested for the preventive treatment of migraine and episodic cluster headache by multiple randomized clinical trials (RCTs) and have been found to reduce headache frequency.

Methods: We systematically searched PubMed and Embase on Cochrane Central Register of Controlled Trials (CENTRAL) from the earliest date to August 1, 2019. Relative risk (RR) and weighted mean difference (WMD) were used to evaluate clinical outcomes.

Results: Seven studies were pooled with 3889 patients. Subcutaneous injection of Galcanezumab at 120 mg, 240 $\mathrm{mg}$ leads to a statistically significant response rate for the treatment of migraine compared with placebo (120 mg: $\mathrm{RR}=1.51 ; 95 \% \mathrm{Cl}, 1.33$ to $1.70 ; P<0.001 ; 240 \mathrm{mg}: \mathrm{RR}=1.58 ; 95 \% \mathrm{Cl}, 1.43$ to $1.76 ; P<0.001$ ). Among them, $120 \mathrm{mg}$ group has the same treatment efficacy with $240 \mathrm{mg}$ group ( $50 \%$ response: $\mathrm{RR}=1.06 ; 95 \% \mathrm{Cl}, 0.92$ to $1.22 ; P=0.425$; $75 \%$ response: $\mathrm{RR}=1.07 ; 95 \% \mathrm{Cl}, 0.94$ to $1.23 ; P=0.301 ; 100 \%$ response; $\mathrm{RR}=1.06 ; 95 \% \mathrm{Cl}, 0.81$ to $1.37 ; P=0.682$; MHD: $\mathrm{RR}=-0.08 ; 95 \% \mathrm{Cl},-0.55$ to $-0.40 ; P=0.748$ ) while related to a lower risk for adverse events for the treatment of migraine (120 mg RR $=1.06 ; 95 \% \mathrm{Cl}, 0.99$ to $1.14 ; P=0.084 ; 240 \mathrm{mg}: \mathrm{RR}=1.17 ; 95 \% \mathrm{Cl}, 1.09$ to $1.25 ; P<0.001) .300 \mathrm{mg}$ per month galcanezumab is effective for the prevention of episodic cluster headache measured by at least $50 \%$ reduction of cluster headache frequency at week $3(\mathrm{RR}=1.36 ; 95 \% \mathrm{Cl}, 1.00-1.84 ; P=0.048)$.

Conclusions: Use of galcanezumab is related to a significantly reduced monthly headache frequency compared with placebo for the treatment of migraine and episodic cluster headache, $120 \mathrm{mg}$ has the same treatment efficacy with 240 $\mathrm{mg}$ group while related to a lower risk for adverse effects for the treatment of migraine. $300 \mathrm{mg}$ per month galcanezumab is effective for the prevention of episodic cluster headache with no significantly increased adverse events.
\end{abstract}

Keywords: Migraine, Cluster headache, Galcanezumab, Meta-analysis

\section{Background}

Migraine and cluster headache are disabling neurologic disorder characterized by severe and repetitive headache attacks. As proposed by the International Headache society, migraine is defined as headache attacks lasting $4-72 \mathrm{~h}$ that are accompanied by nausea, photophobia or

\footnotetext{
*Correspondence: zqchen6@163.com; wangzhong761@163.com

†Yanbo Yang and Zilan Wang contributed equally to this work.

${ }^{1}$ Department of Neurosurgery \& Brain and Nerve Research Laboratory, The First Affiliated Hospital of Soochow University, 188 Shizi Street, Suzhou, Jiangsu Province 215006, China

Full list of author information is available at the end of the article
}

phonophobia, while cluster headache is a strictly unilateral headache that lasts for $15-180 \mathrm{~min}$ and is commonly combined with symptoms that related with parasympathetic activation [1]. Both migraine and cluster headache can lead to severe psychological disturbance $[2,3]$ and have caused a huge economic burden $[4,5]$.

Galcanezumab is a monoclonal antibody that targets to the calcitonin gene-related peptide (CGRP). Increased serum CGRP level is observed after migraine and cluster headache attack in both human and animal models $[6,7]$. Trigeminovascular system-a pain modulating center- 
can release CGRP upon activation [8]. CGRP will, induce potent vasodilatory effects on cerebral arteries [9], modulate the sensitivity of nociceptive trigeminal neurons [10] and subsequently trigger migraine and cluster headache attacks. This process is considered as an initiative step in the pathogenesis of both migraine and cluster headache [11-13]. For decades, CGRP is considered a promising target for treatment of migraine and cluster headache. Previous clinical trials have supported the use of CGRP monoclonal antibodies as a preventive treatment for migraine and episodic cluster headache [14-20]. The development of drugs that targets to CGRP has become a successful translation from bench to clinic [10].

Systemic reviews have confirmed the effectiveness and safety of CGRP monoclonal antibodies for the treatment of migraine and cluster headache [21, 22]. However, until now, no study is conducted to systemically analyze the efficacy and safety profiles of galcanezumab across different doses, therefore, we conducted a meta-analysis to evaluate the dose-related efficacy and tolerability of galcanezumab for the treatment of migraine and cluster headache.

\section{Methods}

A meta-analysis was conducted in accordance with the preferred reporting items for systematic reviews and meta-analyses (PRISMA) guidelines [23].

\section{Search strategy}

Original researches in the PUBMED, EMBASE database and Cochrane Library database were searched up to $\mathrm{Au}$ gust 1, 2019 for relevant published articles. The following search terms were used: galcanezumab, LY2951742, migraine and cluster headache. The reference lists of the relevant articles were all screened to avoid omissions.

\section{Study selection}

All of the studies included in this meta-analysis (1) were all randomized clinical trials (RCTs); (2) enrolled participants with migraine or cluster headache (3) used galcanezumab as intervention; (4) enrolled over 100 participants.

\section{Data extraction}

All the data were extracted independently by 3 investigators (YY, ZW and $\mathrm{ZC})$ and any disagreements were settled through discussion. The extracted data include (1) literature information (title, author, publication time, sample size, etc.); (2) characteristic of the object of the study (age, BMI, smoking status, headache attack status before study); (3) content of the expose or interfere (experiment doses in different groups); (4) outcome data including migraine headache days (MHD), 50\%, 75\%, 100\% response rate, which was defined as a reduction of the frequency of headache attacks by at least given percentage, treatment-emergent adverse events (TEAE), serious adverse events (SAE) and number of patients discontinue. We chose $50 \%$ response rate at the end of each trial as the primary endpoint for migraine, $50 \%$ response rate at week 3 for cluster headache.

\section{Statistical analysis}

In this study, weighted mean differences (WMD) and relative risk (RR) with their 95\% confidence intervals (CIs) were used to evaluate the effect of galcanezumab on migraine or cluster headache. The heterogeneity between the included studies was evaluated with $I^{2}$ and $p$ value. When the $I^{2}>50 \%$ or $p$-value $<0.05$, the data would be regarded as showing conspicuous heterogeneity. Random-effects model was applied to analyze the data. In addition, the researchers divided the subjects into different subgroups according to the dose and time of drug use, and made a subgroup analysis. Details of the subgroup analysis will be described later in the article. STATA 12.0 was used to conduct the analysis.

\section{Risk of Bias}

The risk of bias plot in individual studies was created using the Review Manager 5.2 software. For assessing the risk of bias of RCTs, we applied uniform criteria of the Cochrane collaboration, which included: selection bias, performance bias, detection bias, attrition bias, reporting bias, and other potential biases.

\section{Results}

\section{Search results and study characteristics}

We systematically searched articles published before $\mathrm{Au}$ gust 1, 2019 and identified 651 articles in total that were related to this topic. After removing the duplicate reports, there were 319 reports remaining. Among these, 7 studies were found to be directly related to our study, but one ongoing clinical trial on chronic cluster headache (NCT02438826) was excluded because the trial did not reach its primary endpoint. Lastly, 3889 patients from 6 multi-centered double blinded trials [14-19], one open-labeled clinical trial [20] were pooled. Among them, 6 trails focused on chronic and/or episodic migraine, and one trial on episodic cluster headache. Study selection process was plotted in Fig. 1. Details of the study characteristics are shown in Table 1.

\section{Quality assessment}

Three of the seven studies are at high risk of attrition bias $[15,18,20]$ which can be explained by a relatively high discontinue rate related to prolonged experiment period $[15,20]$ and high proportion of discontinue in placebo group due to lack of efficacy [18]. One study is at high risk of selection bias [20]. We conducted a sensitivity test to evaluate potential bias of the studies involved in our meta-analysis. Of the seven included 
Table 1 Characteristics of the Included Studies and Outcome Events

\begin{tabular}{|c|c|c|}
\hline $\begin{array}{l}\text { Trials Phases } \\
\text { Publication Center }\end{array}$ & Inclusion Criteria & Exclusion Criteria \\
\hline $\begin{array}{l}\text { Oakes, } \\
\text { 2018(NCT02163993 } \\
\text { ) [14] } \\
\text { Phase2b } \\
\text { Cephalalgia } \\
\text { Multicenter }\end{array}$ & $\begin{array}{l}\text { Aged 18-65 years } \\
\text { A diagnosis of episodic migraine for at } \\
\text { least } 1 \text { year prior } \\
\text { Monthly frequency of 4-14 MHD }\end{array}$ & $\begin{array}{l}\text { Failure to respond to three or more } \\
\text { adequately dosed effective migraine } \\
\text { prevention treatments } \\
\text { Prior exposure to any CGRP antibody, any } \\
\text { antibody to the CGRP receptor, or } \\
\text { antibody to NGF } \\
\text { History of migraine subtypes }{ }^{\mathrm{a}}\end{array}$ \\
\hline
\end{tabular}

Stauffer Aged $18-65$ years

2018(NCT02614183 A diagnosis of episodic migraine for at ) [15]

Phase 3 least 1 year prior

JAMA Neurology

Multicenter

Skljarevski Aged $18-65$ years

2018(NCT02614196 A diagnosis of episodic migraine for at ) [16]

Phase 3

Cephalalgia

Multicenter

least 1 year prior least two migraine attacks during the baseline period

Dodick, 2014

(NCT01625988)

[19]

Phase 2

Lancet Neurol

Multicenter

\section{Aged 18-65 years}

A diagnosis of migraine as defined by IHS ICHD-II for at least 1 year prior Monthly frequency of 4-14 MHD

Mulicenter

\section{antibody to NGF
History of migraine subtypes}

Failure to respond to three or more classes of migraine preventive treatments Prior exposure to any CGRP antibody Having taken a therapeutic antibody in the past 12 months

Receiving preventive migraine medication within 30 days

History of persistent daily headache, cluster headache or migraine subtypes

Failure to respond to three or more Prior exposure to any CGRP antibody Having taken a therapeutic antibody in the past 12 months

Using opioids or barbiturates more than twice per month

Known hypersensitivity to multiple drugs

Failure to respond to three or more adequately dosed approved migraine

Receiving preventive migraine medication within 30 days, including receiving botulinum toxin within 4 months

$\begin{array}{ll}\begin{array}{l}\text { Trials Phases } \\ \text { Publication Center }\end{array} & \text { Inclusion Criteria } \\ \text { Detke, } & \text { Aged } 18-65 \text { years } \\ 2018(\text { NCT02614261 } & \text { A diagnosis of chronic migraine for at least } \\ \text { ) [17] } & 1 \text { year prior } \\ \text { Phase 3 } & \text { A history of at least } 15 \text { headache days per } \\ \text { Neurology } & \text { month, of which at least } 8 \text { were migraine } \\ \text { Multicenter } & \text { and a history of at least } 1 \text { headache-free } \\ & \text { day per month for the past } 3 \text { months }\end{array}$

Camporeale,
2018(NCT026142
87) [20]
Phase 3
BMC Neurology
Multi-center

Aged 18-65 years

A diagnosis of migraine for at least 1 year prior

A history of 4 or more MHD per month on average for the past 3 months and a history of at least 1 headache-free day per month for the past 3 months

Goadsby, Aged 18-65 years

2019(NCT02397473 A diagnosis of cluster headache ) [18]

Phase 3
Frequency of at least one attack every other day, at least four total attacks, and classes of migraine preventive treatments prevention treatments History of chronic migraine or migraine subtypes

Patients with at least 15 headache days per 28-day period

Exclusion Criteria

Failure to respond to three or more classes of migraine preventive treatments Prior exposure to any CGRP antibody Having taken a therapeutic antibody in the past 12 months Persistent daily headache, cluster headache, head or neck trauma within the past 6 months, possible posttraumatic headache, or primary headache other than chronic migraine

Receiving preventive migraine medication within 30 days, including receiving

botulinum toxin within 4 months

Condition group

Frequency

$\begin{array}{lll}\text { Episodic } & \text { galcanezumab } & \text { Once } \\ \text { migraine } & 150 \mathrm{mg} & \text { every } 2 \\ & \text { placebo } & \text { weeks for } \\ & & 12 \text { weeks }\end{array}$

Condition group

Frequency

Chronic galcanezumab

migraine $120 \mathrm{mg}$ (with 240-mg loading dose) galcanezumab $240 \mathrm{mg}$ placebo

Failure to respond to three or more classes of migraine preventive treatments Prior exposure to galcanezumab or any other CGRP antibody

Having taken a therapeutic antibody in the past 12 months

Current treatment with preventive migraine medication

Prior exposure to any CGRP antibody, antibody to the CGRP receptor or antibody to NGF

Concurrent use of other therapeutic

\begin{tabular}{|c|c|c|}
\hline $\begin{array}{l}\text { Chronic } \\
\text { and } \\
\text { episodic } \\
\text { migraine }\end{array}$ & $\begin{array}{l}\text { galcanezumab } \\
120 \text { mg (with } \\
240-\text { mg load- } \\
\text { ing dose) } \\
\text { galcanezumab } \\
240 \text { mg }\end{array}$ & $\begin{array}{l}\text { Once a } \\
\text { month for } \\
12 \\
\text { months }\end{array}$ \\
\hline $\begin{array}{l}\text { Episodic } \\
\text { cluster } \\
\text { headache }\end{array}$ & $\begin{array}{l}\text { galcanezumab } \\
300 \mathrm{mg} \\
\text { placebo }\end{array}$ & $\begin{array}{l}\text { Once a } \\
\text { month for } \\
2 \text { months }\end{array}$ \\
\hline
\end{tabular}

Once a month for 3 months

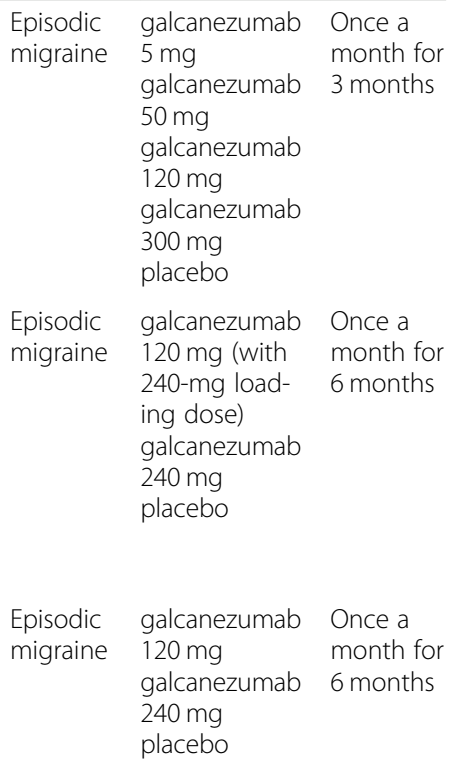

$\begin{array}{lll}\text { Episodic } & \text { galcanezumab } & \text { Once a } \\ \text { migraine } & 5 \mathrm{mg} & \text { month for } \\ & \text { galcanezumab } & 3 \text { months } \\ & 50 \mathrm{mg} & \\ & \text { galcanezumab } & \\ & 120 \mathrm{mg} & \\ & \text { galcanezumab } & \\ & 300 \mathrm{mg} & \\ & \text { placebo } & \\ \text { Episodic } & \text { galcanezumab } & \text { Once a } \\ \text { migraine } & 120 \mathrm{mg} \text { (with } & \text { month for } \\ & 240 \text {-mg load- } & 6 \text { months } \\ & \text { ing dose) } & \\ & \text { galcanezumab } & \\ & 240 \text { mg } & \\ \text { placebo } & \end{array}$

Episodic migraine

galcanezumab

$120 \mathrm{mg}$

Once a $240 \mathrm{mg}$ placebo

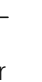
.

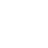


Table 1 Characteristics of the Included Studies and Outcome Events (Continued)

\begin{tabular}{|c|c|c|c|c|}
\hline $\begin{array}{l}\text { Trials Phases } \\
\text { Publication Center }\end{array}$ & Inclusion Criteria & Exclusion Criteria & Condition group & Frequency \\
\hline $\begin{array}{l}\text { N Engl J Med } \\
\text { Multicenter }\end{array}$ & $\begin{array}{l}\text { no more than eight attacks per day during } \\
\text { a baseline assessment } \\
\text { A history of cluster headache periods } \\
\text { lasting at least } 6 \text { weeks } \\
\text { Participants are able to distinguish cluster } \\
\text { headache attacks from other headaches }\end{array}$ & $\begin{array}{l}\text { monoclonal antibodies } \\
\text { Having another distinct trigeminal } \\
\text { autonomic cephalalgia or a history of } \\
\text { migraine variants that could have been } \\
\text { due to cerebral ischemia }\end{array}$ & & \\
\hline
\end{tabular}

MHD Migraine Headache Days, CGRP calcitonin-gene-related peptide, NGF nerve growth factor;

${ }^{a}$ Migraine subtypes including hemiplegic migraine, ophthalmoplegic migraine, and basilar-type migraine

studies, all the studies were at low risk of publication bias. There were six double-blind and one open-label studies, with the latter deemed higher risk of bias but there was no evidence of bias for the primary outcome (Fig. 2).

\section{Efficacy}

Overall, the use of galcanezumab was associated with significant increased response rate compared with placebo
(Additional file 1: Supplement 1). The sensitivity analysis did not substantively alter the overall result (Additional file 1: Supplement 2). When measured by $50 \%$ response rate across different dosage subgroup, subcutaneous injection of galcanezumab with $120 \mathrm{mg}$ and $240 \mathrm{mg}$ doses were related to a significantly increased $50 \%$ response rate compared with placebo group for the treatment of migraine $(120 \mathrm{mg}$ : $\mathrm{RR}=1.51 ; 95 \% \mathrm{CI}, 1.33$ to $1.70 ; P<0.001 ; 240 \mathrm{mg}: \mathrm{RR}=$ 1.58; $95 \% \mathrm{CI}, 1.43$ to $1.76 ; P<0.001$ ) (Fig. 3a) and $5 \mathrm{mg}$ and

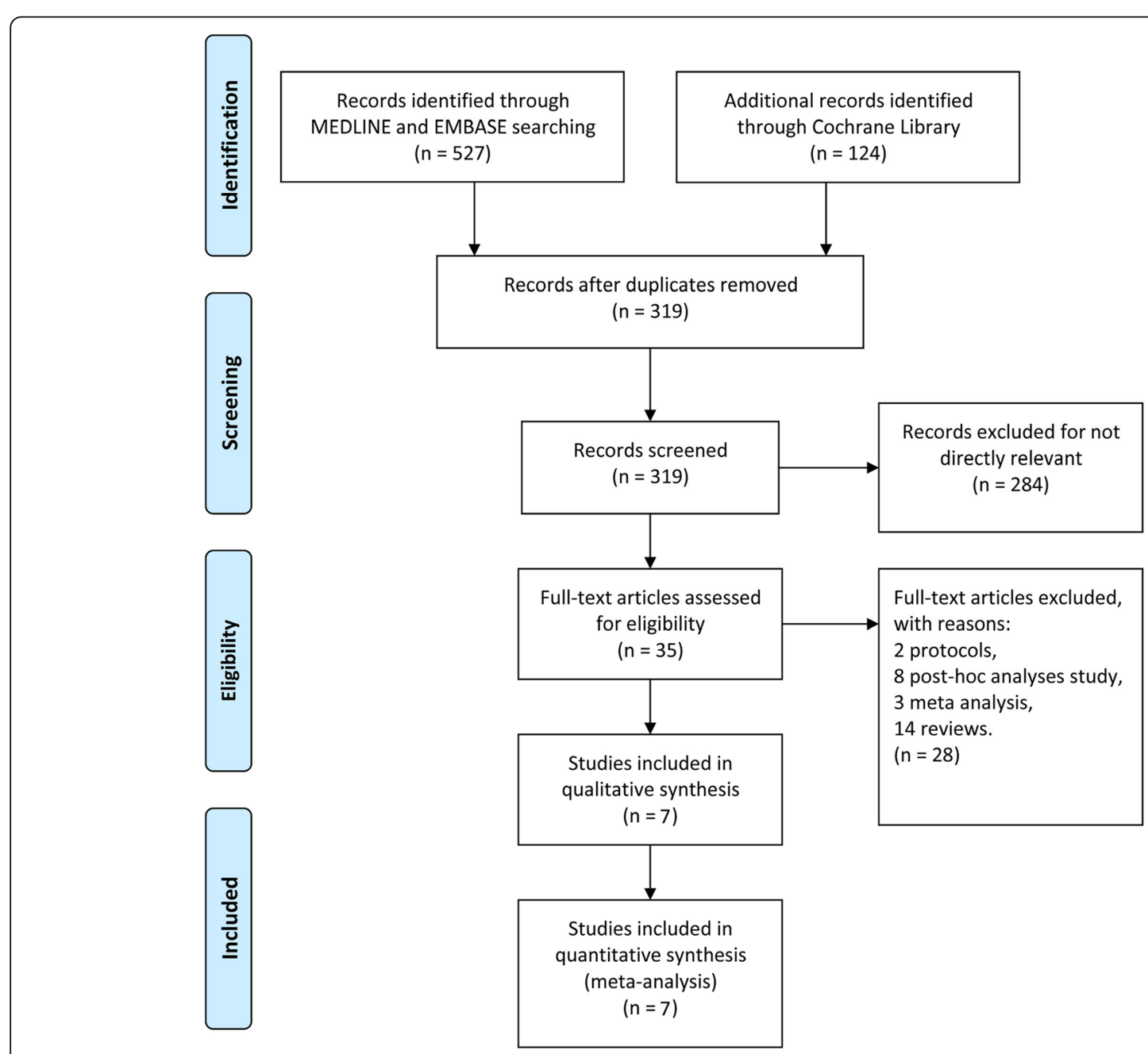

Fig. 1 The study search, selection, and inclusion process 


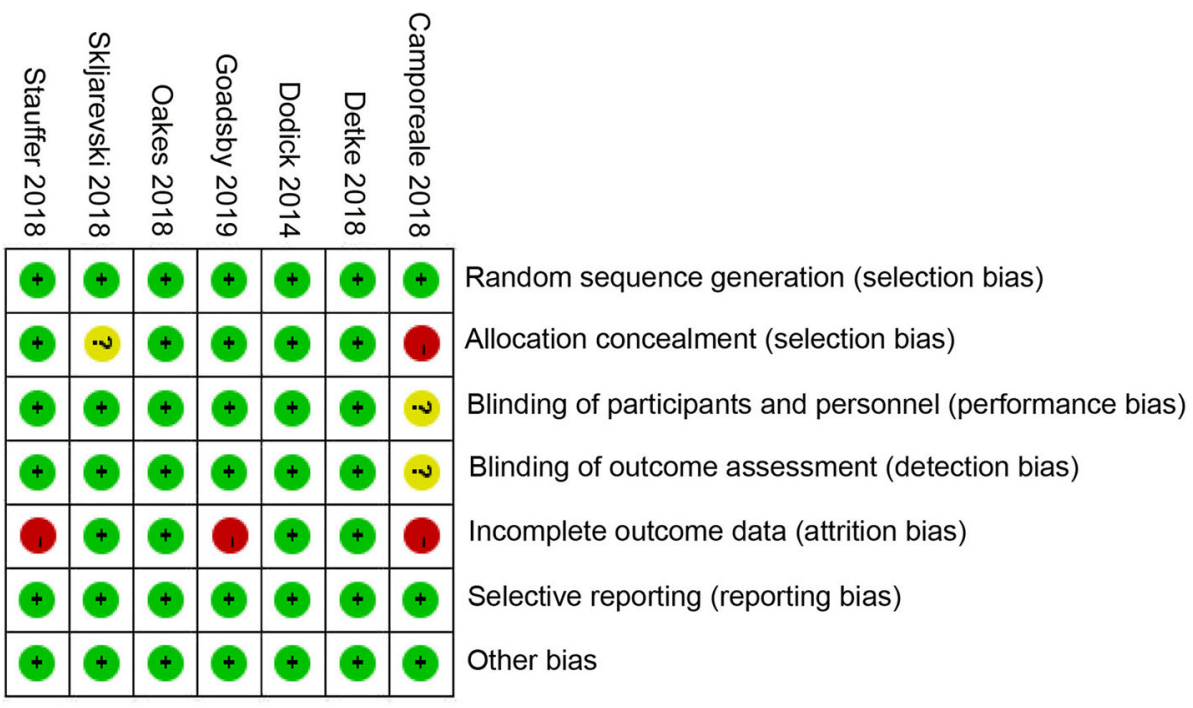

Low risk of bias

$\square$ Unclear risk of bias

High risk of bias

Fig. 2 Summary table for potential bias analysis for included study

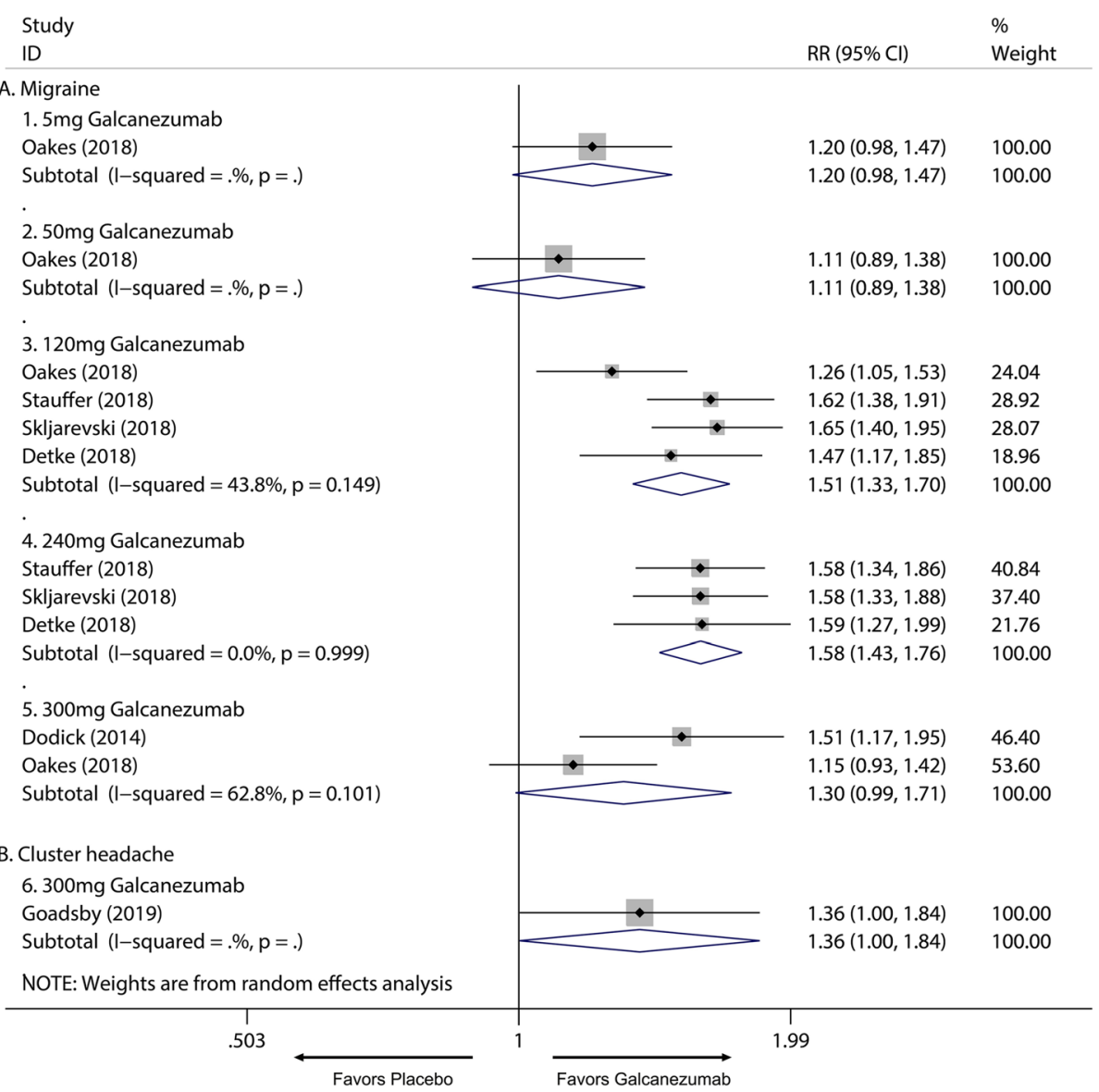

Fig. 3 The pooled relative risk of the 50\% response rate (defined as at least 50\% reduction of headache attack frequency from baseline) in different treatment doses compared with placebo, the diamond indicates the estimated relative risk with $95 \%$ confidence interval for the pooled patients. $R R$ relative risk 
$50 \mathrm{mg}$ doses did not related to increased $50 \%$ response rate compared with placebo ( $5 \mathrm{mg}$ : $\mathrm{RR}=1.20 ; 95 \% \mathrm{CI}, 0.98$ to 1.47; $P=0.071 ; 50 \mathrm{mg}: \mathrm{RR}=1.11 ; 95 \% \mathrm{CI}, 0.89$ to $1.38 ; P=$ 0.367 ) (Fig. 3a). $75 \%$ and $100 \%$ response rate of $120 \mathrm{mg}$ and $240 \mathrm{mg}$ subgroup also had proved this dose-response relationship for the treatment of migraine (Additional file 1: Supplement 3 and Additional file 1: Supplement 4). For MHDs, $120 \mathrm{mg}, 240 \mathrm{mg}$ and $300 \mathrm{mg}$ galcanezumab were associated with significantly reduced MHDs (120 mg: $\mathrm{WMD}=-1.83 ; 95 \% \mathrm{CI},-2.23$ to $-1.43 ; P<0.001 ; 240$ mg: $\mathrm{WMD}=-1.85 ; 95 \% \mathrm{CI},-2.29$ to $-1.40 ; P<0.001$; $300 \mathrm{mg}: \mathrm{WMD}=-0.95,95 \% \mathrm{CI},-1.57$ to $-0.34 ; P=$ 0.002 ) while $5 \mathrm{mg}$ and $50 \mathrm{mg}$ had no significant treatment effect $(5 \mathrm{mg}$ : $\mathrm{WMD}=-0.57 ; 95 \% \mathrm{CI},-1.49$ to $0.35 ; P=0.225 ; 50 \mathrm{mg}: \mathrm{WMD}=-0.26 ; 95 \% \mathrm{CI},-1.16$ to $0.64 ; P=0.572$ ) (Fig. 4). For comparing efficacy of galcanezumab between $120 \mathrm{mg}$ and $240 \mathrm{mg}$ for treatment of migraine, no significant differences in 50\%, $75 \%$,
$100 \%$ response rates and MHDs reduction between 120 $\mathrm{mg}$ and $240 \mathrm{mg}$ group were found $(50 \%$ response: $\mathrm{RR}=$ 1.06; $95 \% \mathrm{CI}, 0.92$ to $1.22 ; P=0.425 ; 75 \%$ response: $\mathrm{RR}=1.07 ; 95 \% \mathrm{CI}, 0.94$ to $1.23 ; P=0.301 ; 100 \%$ response; $\mathrm{RR}=1.06 ; 95 \% \mathrm{CI}, 0.81$ to $1.37 ; P=0.682$; MHD: $\mathrm{RR}=-0.08 ; 95 \% \mathrm{CI},-0.55$ to $-0.40 ; P=0.748$ ) (Fig. 5; Additional file 1: Supplement 5; Additional file 1: Supplement 6; Fig. 6). Sensitivity analysis showed that all of the results were regarded stable (Additional file 1: Supplement 7). For the efficacy of galcanezumab across different timepoints, galcanezumab was effective in reducing MHDs and improve 50\% response rate in both patients with migraine at $120 \mathrm{mg}, 240 \mathrm{mg}$ and 300 $\mathrm{mg}$ dose in any timepoint of interest (Table 2). For the treatment of cluster headache, $300 \mathrm{mg}$ was effective against episodic cluster headache measured by $50 \%$ response rate at week 3 compared with placebo. $(\mathrm{RR}=$ 1.36; $95 \% \mathrm{CI}, 1.00$ to $1.84 ; P=0.048$ ) (Fig. $3 \mathrm{~b}$ ).

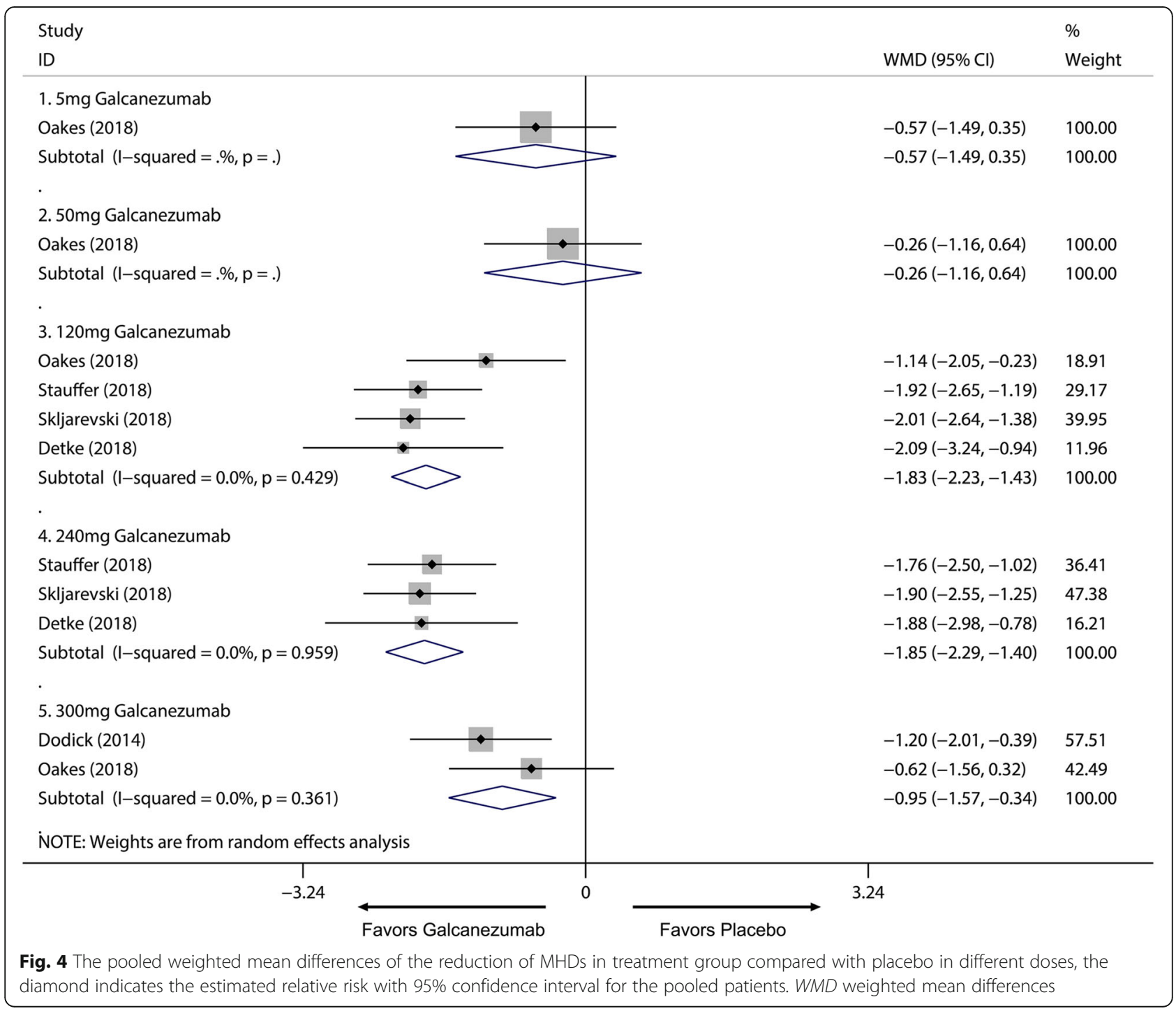




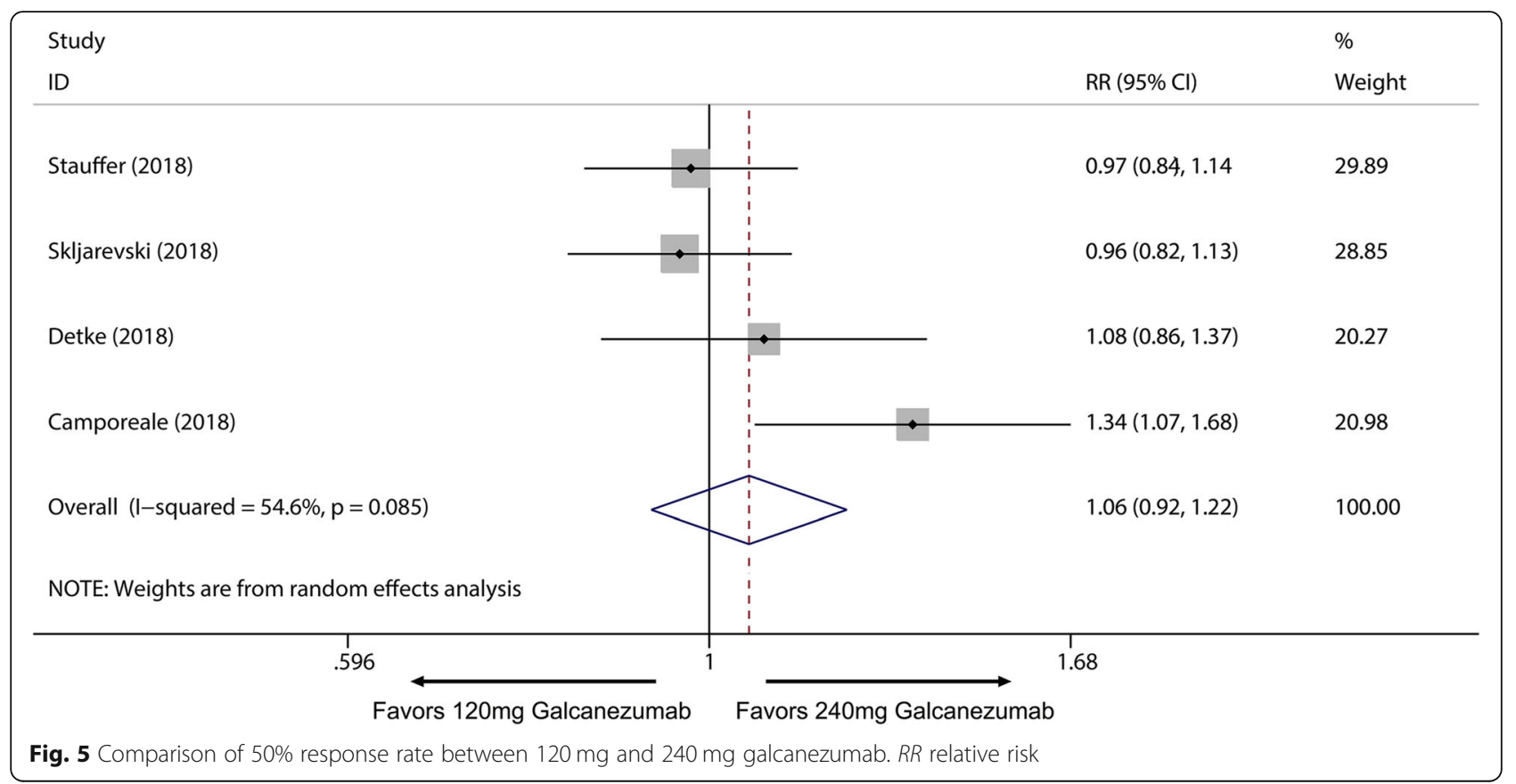

\section{Tolerance, adverse effect, and adherence}

Of all the 2133 patients receiving galcanezumab, no deaths occurred during the experiment period. The most frequently reported adverse effects were injection site pain and upper respiratory infections. Subsequently, a subgroup analysis was performed to examine the difference in TEAEs and SAEs on effective treatment doses for migraine. We found $120 \mathrm{mg}$ group had no significant difference in TEAEs compared with placebo group $(R R=$
1.06; 95\% CI, 0.99 to 1.14; $P=0.084$ ) (Fig. 7.1), and a higher frequency of adverse events in the $240 \mathrm{mg}$ group than placebo group was identified $(\mathrm{RR}=1.17 ; 95 \% \mathrm{CI}$, 1.09 to $1.25 ; P<0.001$ ) (Fig. 7.2). Moreover, $120 \mathrm{mg}$ and $240 \mathrm{mg}$ group had a significant increase in serious adverse effects frequency than placebo group (120 mg: $\mathrm{RR}=2.10$; $95 \% \mathrm{CI}, 1.02$ to $4.36 ; P=0.045 ; 240 \mathrm{mg}: \mathrm{RR}=$ 2.75; $95 \% \mathrm{CI}, 1.38$ to $5.47 ; P=0.004$ ) (Fig. 8 ). For the comparing adverse events of galcanezumab between $120 \mathrm{mg}$

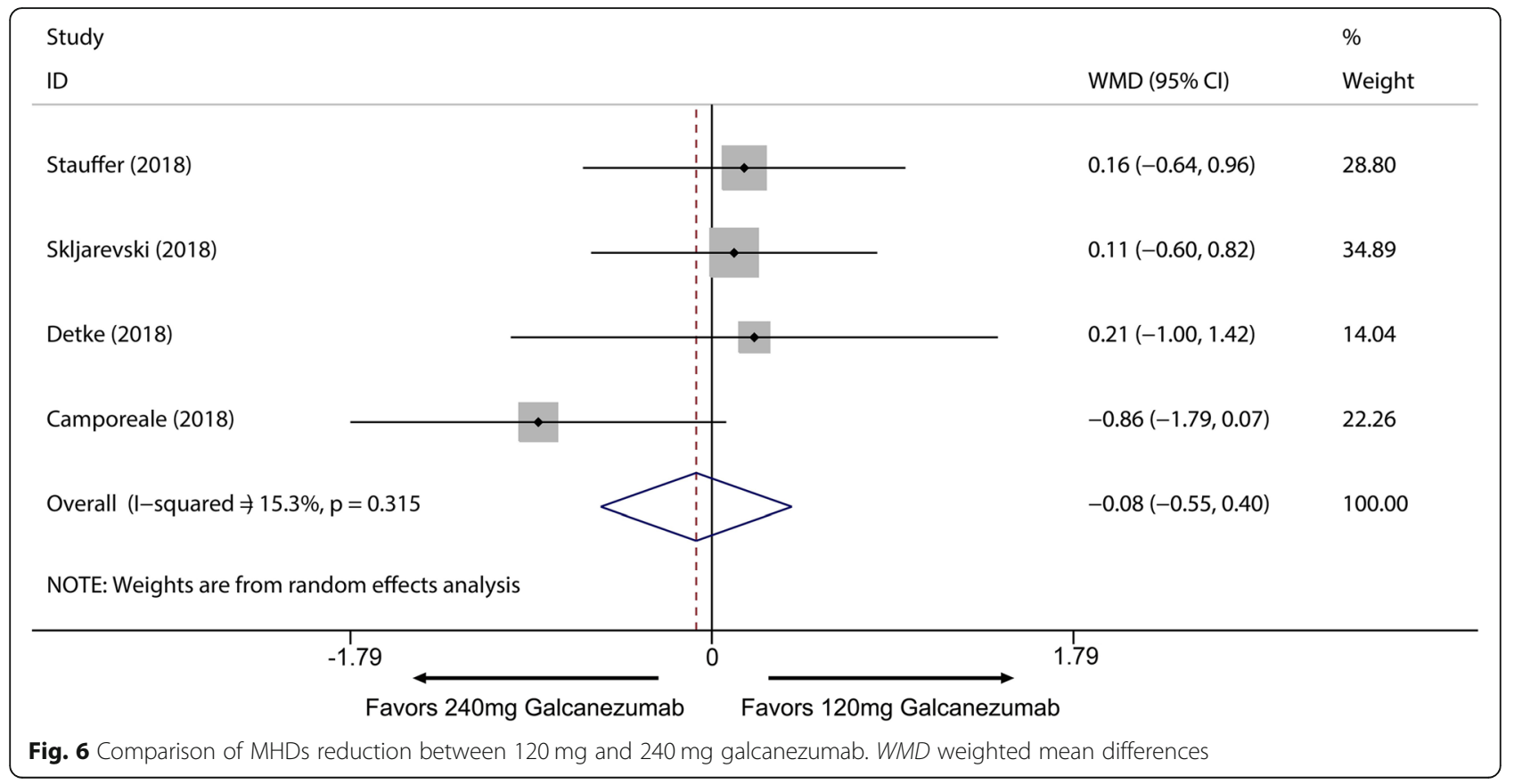


Table 2 Subgroup analysis of efficacy and safety outcome of galcanezumab for the treatment of migraine

\begin{tabular}{|c|c|c|c|c|c|c|}
\hline & \multicolumn{4}{|l|}{ Efficacy } & \multirow{2}{*}{\multicolumn{2}{|c|}{$\frac{\text { Safety }}{\text { TEAE }}$}} \\
\hline & \multicolumn{2}{|l|}{$50 \% \geq$ response } & \multicolumn{2}{|l|}{$\mathrm{MHD}$} & & \\
\hline & $\mathrm{RR}(95 \% \mathrm{Cl})$ & $P$ value & WMD (95\% Cl) & $P$ value & $\mathrm{RR}(95 \% \mathrm{Cl})$ & $P$ value \\
\hline \multicolumn{7}{|c|}{ 1. $120 \mathrm{mg}$ Galcanezumab } \\
\hline 3 months & $1.469(1.166,1.850)$ & 0.006 & $-2.090(-3.237,-0.943)$ & 0.000 & $1.144(1.003,1.304)$ & 0.045 \\
\hline 6 months & $1.513(1.286,1.779)$ & 0.013 & $-1.774(-2.256,-1.291)$ & 0.000 & $1.033(0.950,1.123)$ & 0.443 \\
\hline \multicolumn{7}{|c|}{ 2. $240 \mathrm{mg}$ Galcanezumab } \\
\hline 3 months & $1.589(1.270,1.987)$ & 0.013 & $-1.880(-2.983,-0.777)$ & 0.001 & $1.155(1.014,1.316)$ & 0.030 \\
\hline 6 months & $1.582(1.406,1.780)$ & 0.000 & $-1.839(-2.324,-1.354)$ & 0.000 & $1.170(1.082,1.266)$ & 0.000 \\
\hline \multicolumn{7}{|c|}{ 3. 300 mg Galcanezumab } \\
\hline 1 month & N/A & N/A & N/A & N/A & $1.286(0.788,2.097)$ & 0.314 \\
\hline 3 months & $1.509(1.166,1.954)$ & 0.000 & $-1.200(-2.012,-0.388)$ & 0.004 & $1.087(0.927,1.275)$ & 0.302 \\
\hline 6 months & $1.147(0.928,1.418)$ & 0.000 & $-0.620(-1.565,0.325)$ & 0.198 & $0.935(0.693,1.261)$ & 0.659 \\
\hline
\end{tabular}

RR Relative Risk, Cl Confidence Interval, N/A Not Applicable

and $240 \mathrm{mg}, 120 \mathrm{mg}$ galcanezumab is related to decreased risks for TEAEs and AEs compared with $240 \mathrm{mg}$ galcanezumab (Fig. 9). For safety of galcanezumab at effective treatment dose $(300 \mathrm{mg})$ for episodic cluster headache, the pooled data showed $300 \mathrm{mg}$ galcanezumab is not related with significant increased risks for TEAEs and SAEs compared with placebo (TEAEs: $\mathrm{RR}=0.93 ; 95 \% \mathrm{CI}, 0.93$ to 1.22; $P=0.340$; SAEs: $\mathrm{RR}=0.79 ; 95 \% \mathrm{CI}, 0.25$ to $2.47 ; P=$ 0.688) (Fig. 10).

Then we plotted the discontinue rate for patients after receiving galcanezumab for 3 months, 6 months and 12 months, which demonstrates in the treatment groups,

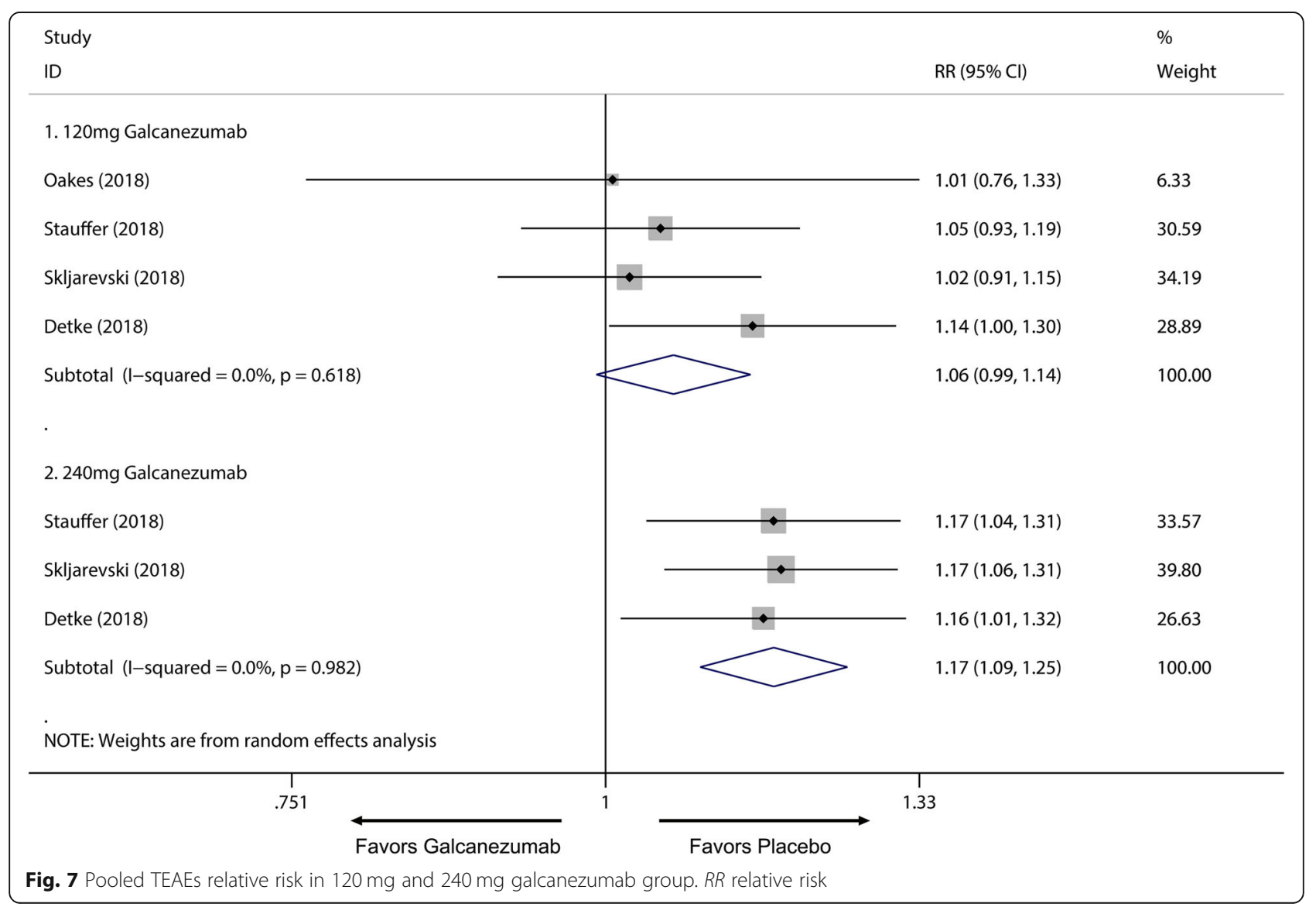




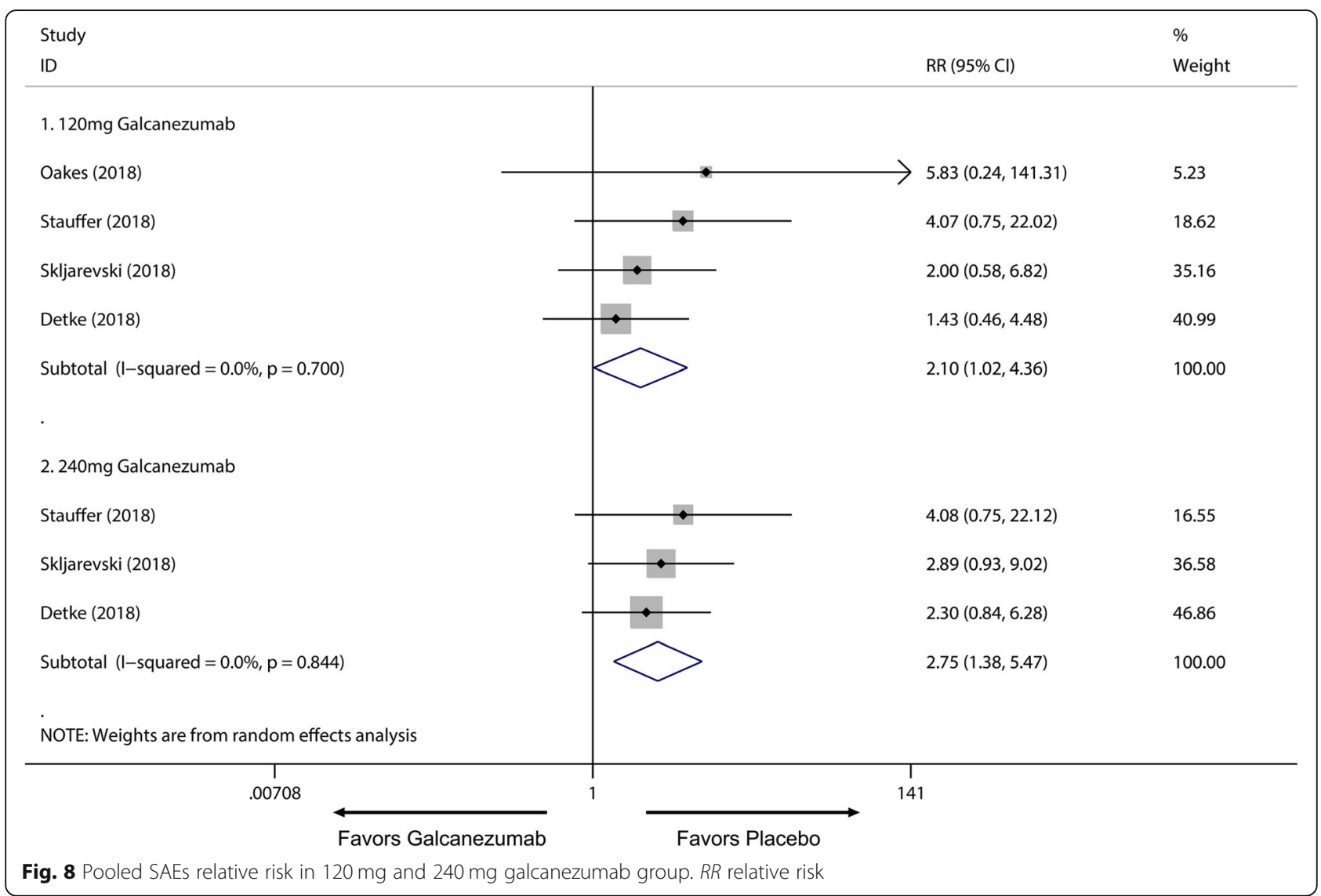

the discontinue rate was uniformly lower compared to placebo group, with an average 6 months discontinue rate of $14.24 \%$ (Table 3 ).

\section{Discussion}

Our study is the first meta-analysis of the clinical use of galcanezumab in the treatment of migraine and cluster headache. It has revealed that the use of galcanezumab is related to a significantly reduced monthly headache frequency compared with placebo group with a relatively safe profile. Subsequently, for the does-response relationship, our data suggest that $120 \mathrm{mg}$ galcanezumab per month is superior for treatment of migraine than 240 $\mathrm{mg}$ per month and $300 \mathrm{mg}$ galcanezumab is effective for the treatment of episodic cluster headache with no significantly increased risk for adverse events.

We pooled 3889 subjects from 7 randomized clinical studies. First, we proved that $120 \mathrm{mg}, 240 \mathrm{mg}$ galcanezumab per month is effective for the treatment migraine when measured by response rate. Then, we analyzed the safety profile of galcanezumab for the treatment of migraine by comparing TEAEs and SAEs across different doses, which showed $240 \mathrm{mg}$ group is related to increased TEAEs and SAEs compared with placebo group. To compare different doses on the treatment of migraine, we performed a subgroup analysis of $120 \mathrm{mg}$ and $240 \mathrm{mg}$ subgroup which demonstrated that $120 \mathrm{mg}$ group has a significant lower rate of TEAEs compared with $240 \mathrm{mg}$ group while has no significant difference on the reduction of headache frequency for the treatment of migraine, it further supports the use of galcanezumab in a dose of $120 \mathrm{mg}$ per month. Moreover, we also demonstrated that $300 \mathrm{mg}$ galcanezumab is effective against episodic cluster headache when measured by response rate and have no significantly increased risk for causing adverse events. Spontaneous relieving is observed in episodic cluster headache by previous studies [24], as a result, we chose $50 \%$ response rate at week 3 as our primary efficacy endpoint which is the secondary endpoint in the original research. One ongoing clinical trial of galcanezumab for the preventive treatment of chronic cluster headache was excluded from of study due to it didn't reach its primary endpoint. Overall, it adds some evidence to the use of the novel drug type: CGRP monoclonal antibody in preventive therapy for episodic cluster headache and migraine.

As increased CGRP level is found to be highly correlated with headache attacks, it has becoming a promising target for headache relieving for decades. Direct CGRP receptor antagonists have been used for 


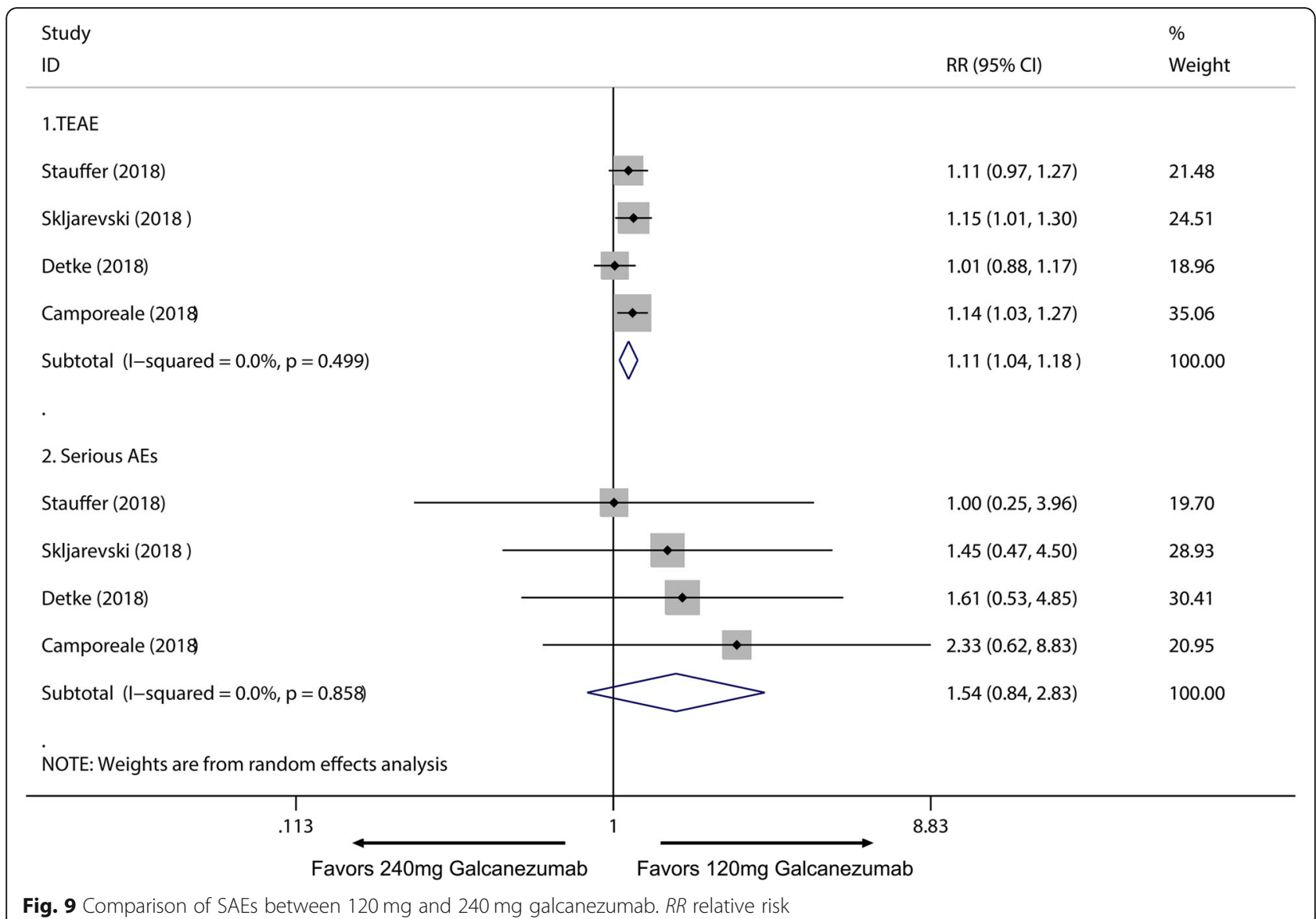

the acute attack management while CGRP monoclonal antibodies are been used on the preventive treatment. Previous studies have demonstrated the similarity on pathogenesis of migraine and cluster headache on pathogenesis and their close relationship with CGRP [25]. Currently proved CGRP monoclonal antibodies have great efficacy against migraine and episodic cluster headache. Efficacy of CGRP monoclonal antibodies has been surveyed by multiple clinical studies and meta-analysis [21]. Most of these studies has positive results regarding to its effectiveness in pain relieving.

Although Galcanezumab has a significant beneficial effect and is related to a lower risk for discontinue compared with placebo that is demonstrated by our research, the overall $100 \%$ response rate suggests the combination of subcutaneous infusion of galcanezumab with acute pain management is required to reach a superior clinical outcome. Thus, further studies are needed to reveal the overall outcome and potential interaction of combining galcanezumab with traditional therapies or direct CGRP receptor antagonists for the treatment of migraine and cluster headache.
Lack of adherence is one of the major problems in chronic disease prevention, this is also encountered by many other traditional preventive pharmacological treatments for migraine or cluster headache discontinue and self-changing of the drug is common in patient [26-29]. Discontinue can be related to bothersome adverse effects, high frequency of dosing or lack of efficacy. As we analyzed in our study, galcanezumab has a rather safe profile, with no mortality reported in all 7 clinical trials and no severe adverse event that is considered directly related to the use of the drug. One major advantage of galcanezumab is it only need to be administrated once monthly, this can be attributed to the long half-life of monoclonal antibodies. Furthermore, the incidence of discontinue is higher in placebo group than in the treatment group, which may contribute to the efficacy of the drug. Interestingly, in our pooled data, we observed a gradual increase in discontinue rate over time, which leads to a discontinue rate of $22.22 \%$ at 12 month which is still dramatically lower than $44 \%$ for traditional preventive therapy that was reported by previous retrospective cohort study [26]. However, because of the long disease course in these 


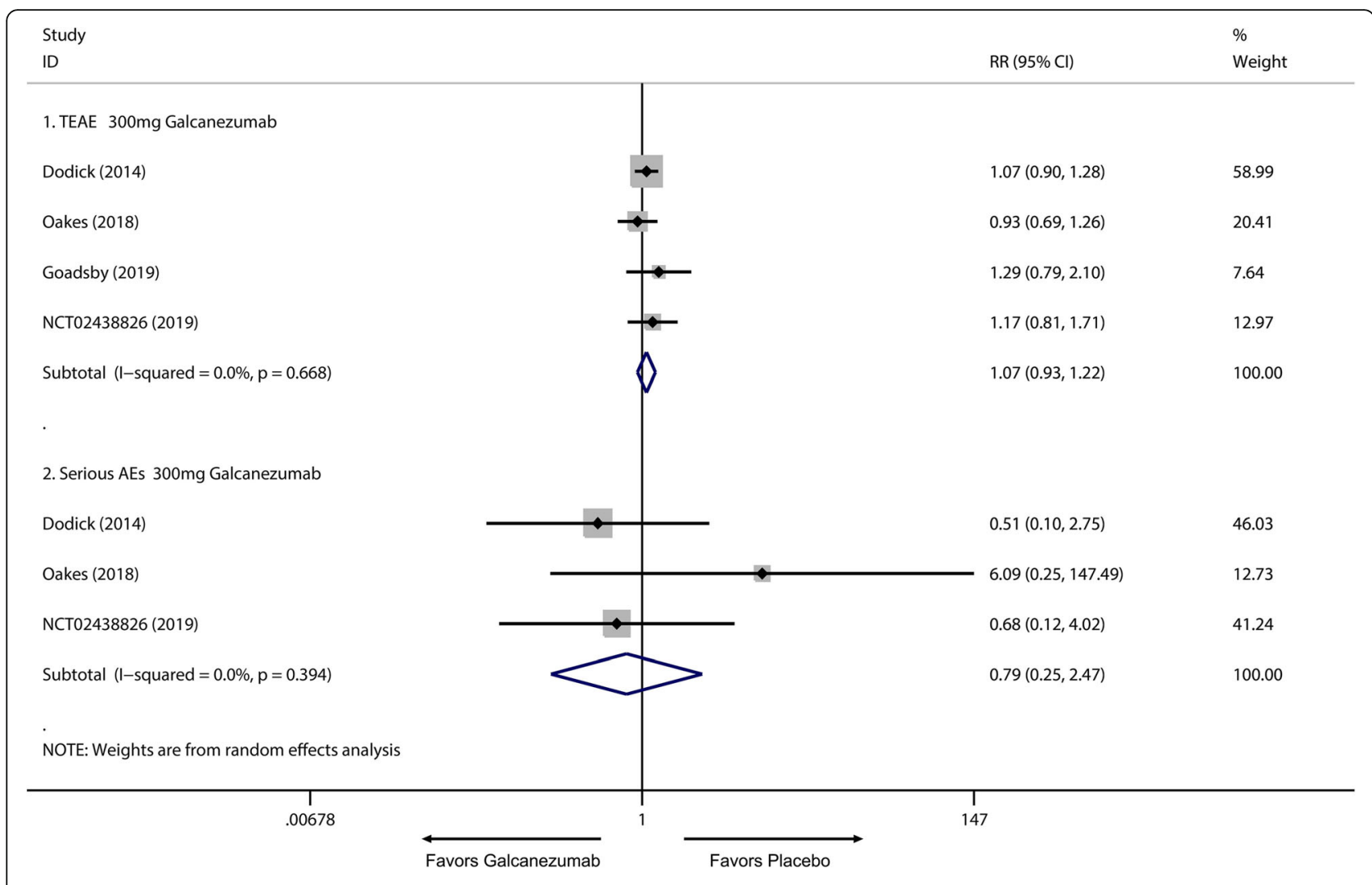

Fig. 10 Pooled SAEs relative risk in $300 \mathrm{mg}$ galcanezumab compared with placebo. $R R$ relative risk

two diseases, further research should be undertaken to investigate patient adherence in a long-term setting.

Recent studies have not been restricted by testing galcanezumab for pain relieving on central nervous system, in 2018, Jin et al. conducted a randomized, placebo-controlled multi-center study investigating efficacy of galcanezumab on patients with knee osteoarthritis, however, it returns with negative result [30]. Because of the heterogeneity of the disease and lack of total adverse effect reported, we excluded this study form our meta-analysis.

One major limitation of our study is lack of enough clinical trials on cluster headache. The only included article for cluster headache targets at testing $300 \mathrm{mg}$ galcanezumab for the treatment of episodic cluster headache [18], with a small sample size, caution must be applied for interpreting its clinical evidence. Plus, our study lakes the clinical data for chronic cluster headache trails. Another limitation for our study is lack of direct

Table 3 Time dependent discontinue rate in treatment group compared with placebo

\begin{tabular}{llll}
\hline & 3 month & 6 month & 12 month \\
\hline Placebo & $9.28 \%$ & $16.78 \%$ & N/A \\
Treatment & $5.74 \%$ & $14.24 \%$ & $22.22 \%$ \\
\hline
\end{tabular}

N/A Not Applicable comparison of treating patients with galcanezumab versus previously used preventive therapies due to lack of large scaled RCTs. Lastly, our study is not able to gather enough data to demonstrate the time-response relationship of the drug due to lack of individual patient data.

\section{Conclusion}

Use of galcanezumab for the treatment of primary headaches have a promising clinical application, it is related to a significantly reduced monthly headache frequency for the treatment of migraine and episodic cluster headache. As for the dose-response relationship, $120 \mathrm{mg}$ has the same treatment efficacy with $240 \mathrm{mg}$ group while related to a lower risk for adverse effects for the treatment of migraine. Thus, based on current studies, $120 \mathrm{mg}$ per month is a preferred treatment method for migraine. Moreover, $300 \mathrm{mg}$ per month galcanezumab is effective against episodic cluster headache that was proved by one randomized clinical trial and the use of $300 \mathrm{mg}$ galcanezumab is not related to an increased risk for adverse events. Major limitation of this study is the lack of the clinical outcome of long-term use, thus, further studies are required to evaluate efficacy and safety in a long-term setting. 


\section{Supplementary information}

Supplementary information accompanies this paper at https://doi.org/10. 1186/s10194-020-1085-x

Additional file 1: Supplement I. $\geq 50 \%, \geq 75 \%$ and $100 \%$ reduction in baseline monthly headache days for galcanezumab versus placebo in the treatment of migraine. Supplement II. Sensitivity analysis of $\geq 50 \%$ reduction in baseline monthly headache days for galcanezumab versus placebo showed that all of the consolidated results were stable.

Supplement III. $\geq 75 \%$ reduction in baseline monthly headache days for $120 \mathrm{mg}$ and $240 \mathrm{mg}$ galcanezumab versus placebo. Supplement IV $100 \%$ reduction in baseline monthly headache days for $120 \mathrm{mg}$ and 240 mg galcanezumab versus placebo. Supplement V. $\geq 75 \%$ reduction in baseline monthly headache days for $120 \mathrm{mg}$ galcanezumab versus 240 mg galcanezumab. Supplement VI. 100\% reduction in baseline monthly headache days for $120 \mathrm{mg}$ galcanezumab versus $240 \mathrm{mg}$ galcanezumab. Supplement VII. Sensitivity analysis of $\geq 50 \%$ reduction in baseline monthly headache days for $120 \mathrm{mg}$ galcanezumab versus $240 \mathrm{mg}$ galcanezumab showed that all of the consolidated results were stable.

\section{Abbreviations}

CGRP: Calcitonin gene-related peptide; Cl: Confidence intervals;

PRISMA: Preferred reporting items for systematic reviews and meta-analyses; RCTs: Randomized clinical trials; RR: Relative risk; SAE: Serious adverse events; TEAE: Treatment-emergent adverse events; WMD: Weighted mean differences

\section{Acknowledgments}

We thank all the participants for their support of this research.

\section{Authors' contributions}

$Y Y, Z W, B G, H X, Y Z, Z C$ and $Z W$ were major contributors in conceiving and writing the manuscript. $Y Y, Z W$, and $Z C$ wrote the paper with input from all authors. ZC and ZW conceived the study and were in charge of overall direction and planning. All authors read and approved the final manuscript.

\section{Funding}

This work was supported by the Suzhou Health Talents Training Project (GSWS2019002).

\section{Availability of data and materials}

All data generated or analyzed during this study are included in this review.

\section{Ethics approval and consent to participate}

Not applicable.

\section{Consent for publication}

Not applicable.

\section{Competing interests}

The authors declare no competing interests.

\section{Author details}

'Department of Neurosurgery \& Brain and Nerve Research Laboratory, The First Affiliated Hospital of Soochow University, 188 Shizi Street, Suzhou, Jiangsu Province 215006, China. ²Department of Cardiology, The First Affiliated Hospital of Soochow University, Suzhou, Jiangsu Province 215006, China.

Received: 25 November 2019 Accepted: 4 February 2020

Published online: 11 February 2020

\section{References}

1. Headache Classification Committee of the International Headache Society (IHS) (2018) The International Classification of Headache Disorders, 3rd edition. Cephalalgia 38(1):1-211

2. Robbins MS (2013) The psychiatric comorbidities of cluster headache. Curr Pain Headache Rep 17(2):313
3. Buse DC et al (2010) Sociodemographic and comorbidity profiles of chronic migraine and episodic migraine sufferers. J Neurol Neurosurg Psychiatry 81(4):428-432

4. Disease GBD, Injury I, Prevalence C (2017) Global, regional, and national incidence, prevalence, and years lived with disability for 328 diseases and injuries for 195 countries, 1990-2016: A systematic analysis for the global burden of Disease study 2016. Lancet 390(10100):1211-1259

5. Gaul C et al (2011) Treatment costs and indirect costs of cluster headache: a health economics analysis. Cephalalgia 31(16):1664-1672

6. Goadsby PJ, Edvinsson L, Ekman R (1988) Release of vasoactive peptides in the extracerebral circulation of humans and the cat during activation of the trigeminovascular system. Ann Neurol 23(2):193-196

7. Goadsby PJ, Edvinsson L, Ekman R (1990) Vasoactive peptide release in the extracerebral circulation of humans during migraine headache. Ann Neurol 28(2):183-187

8. Goadsby PJ, Edvinsson L (1994) Human in vivo evidence for trigeminovascular activation in cluster headache. Neuropeptide changes and effects of acute attacks therapies. Brain 117(Pt 3):427-434

9. Edvinsson L et al (1985) Perivascular peptides relax cerebral arteries concomitant with stimulation of cyclic adenosine monophosphate accumulation or release of an endothelium-derived relaxing factor in the cat. Neurosci Lett 58(2):213-217

10. Edvinsson $L$ et al (2018) CGRP as the target of new migraine therapies successful translation from bench to clinic. Nat Rev Neurol 14(6):338-350

11. Goadsby PJ, Edvinsson L (1993) The trigeminovascular system and migraine: studies characterizing cerebrovascular and neuropeptide changes seen in humans and cats. Ann Neurol 33(1):48-56

12. Goadsby PJ et al (2017) Pathophysiology of migraine: a disorder of sensory processing. Physiol Rev 97(2):553-622

13. Hoffmann J, May A (2018) Diagnosis, pathophysiology, and management of cluster headache. Lancet Neurol 17(1):75-83

14. Oakes TMM et al (2018) Safety of galcanezumab in patients with episodic migraine: a randomized placebo-controlled dose-ranging phase $2 \mathrm{~b}$ study. Cephalalgia 38(6):1015-1025

15. Stauffer VL et al (2018) Evaluation of Galcanezumab for the prevention of episodic migraine: the EVOLVE-1 randomized clinical trial. JAMA Neurol 75(9):1080-1088

16. Skljarevski $V$ et al (2018) Efficacy and safety of galcanezumab for the prevention of episodic migraine: results of the EVOLVE-2 phase 3 randomized controlled clinical trial. Cephalalgia 38(8):1442-1454

17. Detke HC et al (2018) Galcanezumab in chronic migraine: the randomized, double-blind, placebo-controlled REGAIN study. Neurology 91(24):e2211e2221

18. Goadsby PJ et al (2019) Trial of Galcanezumab in prevention of episodic cluster headache. N Engl J Med 381(2):132-141

19. Dodick DW et al (2014) Safety and efficacy of LY2951742, a monoclonal antibody to calcitonin gene-related peptide, for the prevention of migraine: a phase 2, randomised, double-blind, placebo-controlled study. Lancet Neurol 13(9):885-892

20. Camporeale A et al (2018) A phase 3, long-term, open-label safety study of Galcanezumab in patients with migraine. BMC Neurol 18(1):188

21. Zhu Y et al (2018) The efficacy and safety of calcitonin gene-related peptide monoclonal antibody for episodic migraine: a meta-analysis. Neurol Sci 39(12):2097-2106

22. Xu D et al (2019) Safety and tolerability of calcitonin-gene-related peptide binding monoclonal antibodies for the prevention of episodic migraine - a meta-analysis of randomized controlled trials. Cephalalgia 39(9):1164-1179

23. Liberati A et al (2009) The PRISMA statement for reporting systematic reviews and meta-analyses of studies that evaluate healthcare interventions: explanation and elaboration. BMJ 339:b2700

24. Lipton RB et al (1995) Guidelines for controlled trials of drugs in cluster headache. Cephalalgia 15(6):452-462

25. Vollesen AL et al (2018) Migraine and cluster headache - the common link. Jeadache Pain 19(1):89

26. Lafata JE et al (2010) The use of migraine preventive medications among patients with and without migraine headaches. Cephalalgia 30(1):97-104

27. Berger A et al (2012) Adherence with migraine prophylaxis in clinical practice. Pain Pract 12(7):541-549

28. Hepp $Z$ et al (2017) Persistence and switching patterns of oral migraine prophylactic medications among patients with chronic migraine: a retrospective claims analysis. Cephalalgia 37(5):470-485 
29. Vatzaki E et al (2018) Latest clinical recommendations on valproate use for migraine prophylaxis in women of childbearing age: overview from European medicines agency and European headache federation. J Headache Pain 19(1):68

30. Jin Y et al (2018) CGRP blockade by galcanezumab was not associated with reductions in signs and symptoms of knee osteoarthritis in a randomized clinical trial. Osteoarthr Cartil 26(12):1609-1618

\section{Publisher's Note}

Springer Nature remains neutral with regard to jurisdictional claims in published maps and institutional affiliations.

Ready to submit your research? Choose BMC and benefit from:

- fast, convenient online submission

- thorough peer review by experienced researchers in your field

- rapid publication on acceptance

- support for research data, including large and complex data types

- gold Open Access which fosters wider collaboration and increased citations

- maximum visibility for your research: over $100 \mathrm{M}$ website views per year

At $\mathrm{BMC}$, research is always in progress.

Learn more biomedcentral.com/submissions 